\title{
Sir Frederick Dainton to be Chairman of the UGC
}

Sir Frederick Dainton, Dr Lees Professor of Chemistry at the University of Oxford and chairman of the Advisory Board of the Research Councils (ABRC) is to succeed $\mathrm{Sir}$ Kenneth Berrill as chairman of the University Grants Committee later this year.

As forecast in last week's Nature, Sir Kenneth is to succeed Sir Donald MacDougall as the government's Chief Economic Adviser, but the announcement of Sir Frederick's appointment comes as a complete surprise.

Sir Frederick has played a part in government science for several years and before he was appointed chairman of the ABRC on its inception last year he was chairman of the now defunct Council for Scientific Policy. But Sir Frederick is not cutting himself off entirely from the ABRC for his new position entitles him to a seat on that council. The University of Oxford, however, will be that much poorer for Sir Frederick is resigning his position as $\mathrm{Dr}$ L.ees Professor of Chemistry.

The decision to leave academic life, said Sir Frederick this week, was one of the hardest that he has had to make. He will miss working with young people and he will miss as well teaching and

\section{Pay System Reveiw}

THE government agreed late last week to refer the question of scientists' pay within the Civil Service to an independent review by the recently set up Pay Board. This review will take place in the second part of the year.

The government has also agreed that it will be the long term basis of determining scientists pay that will be under review and this will not be influenced solely by short term economic considerations.

Both the official side and the Institution of Professional Civil Servants will be bound by the Pay Board's decision. The IPCS has been demanding an alternative to the current pay research system for eighteen months, but, until now, the government has failed to agree to an independent review. Under pay research the salaries of scientists working in the Civil Service is decided by comparison with the pay of scientists in industry. research. But Sir Frederick is adamant that he will still keep an active interest in science.

The Advisory Board for the Research Councils, which has now been at work since the autumn, has proved to be more successful than Sir Frederick had at first hoped. It has been a successful forum for the government departments to air their thoughts about research and as a result a great deal of mutual confidence has been built up between the research councils and the departments.

Commenting on the recent government white paper which will change the balance of arts and science students in British universities in the next five years in favour of the arts side, Sir Frederick said that he is concerned that well qualified non-scientists are unable to secure places in universities. In many cases the

\section{ECLIPSE}

\section{Science with Concorde}

THE Science Research Council is to provide $f 40,000$ for the support of experiments to study the total eclipse of the sun which will be observed from North Africa on June 30.

There will be two sets of experiments. The first, consisting of five or six experiments, will be carried out by British, French and United States scientists on board Concorde 001, while the second, which will be a collaborative venture with scientists from the United States and Canada will be on an Aerobee rocket which will be supplied by the Kitt Peak National Observatory in Arizona.

The British experiments aboard the Concorde will be prepared by scientists from the University of Aberdeen and Queen Mary College, University of London. The British contribution to the experiments aboard the Aerobee rocket will come from the Astrophysics Research Division of the Science Research Council's Radio and Space Research Station and Imperial College, University of London.

The Concorde flight will start from Las Palmas in the Canary Islands and will join the path of the eclipse in Mauritania in West Africa at 10.45 a.m. Greenwich Mean Time on June 30. It will follow the eclipse for almost an hour and a half covering 1,900 miles in that time. This will extend the possible observing time to eleven times that which qualifications of these art students are better than those of the science students who do manage to get a place. But the white paper will do much to remove this inequity.

Looking to the future and the consequences of a differing rate of growth of the student population and the science budget in the coming years, Sir Frederick said that he is not completely adverse to the concept of university lecturers who do not research. But such lecturers, said Sir Frederick "should breathe the air of a good research department". Sir Frederick also said that it is a bad thing to make a good teacher, who is a reluctant researcher, actually do research. By the same token a good researcher who has no interest in teaching should not be forced to teach.

will be possible for ground based observers. It is planned that the aircraft will fly at 60,000 feet and so will be well above the layers of the atmosphere which absorb infrared radiation. The French contribution to the cost of the flight will be $£ 130,000$.

The University of Aberdeen experiment aboard Concorde will be designed to observe, through a side window in the aircraft, radiation from the near infrared region which is emitted from the stratosphere and mesosphere. From these observations, Dr M. Gadsden of Aberdeen and colleagues hope to deduce the decay times of metastable molecular oxygen. Spectra will also be taken from different heights in the atmosphere in order to determine how the decay time varies with height.

The other British experiment aboard Concorde will be operated by Dr J. E. Beckman and colleagues at Queen Mary College, and it will be designed to obtain a spectrum of the chromosphere in the sub-millimeter region. In order to obtain this spectrum a rapid scan Michelson interferometer with a detector cooled by liquid helium will be used.

The British teams will be joined in the Aerobee experiments by teams from York University in Toronto and Harvard College Observatory, while Kitt Peak National Observatory will provide the rocket, launch and recovery operations. The rocket will be launched from a site in Mauritania near Nouadhibou at 10.33 a.m. Greenwich Mean Time on June 30 . 